\title{
UNA APROXIMACION AL REALISMO DE XAVIER ZUBIRI
}

\author{
Silvia L. Brussino
}

\begin{abstract}
"Busquemos como buscan los que aún no han encontrado y encontremos como encuentran los que aún han de buscar". . . La frase agustiniana con que Zubiri tantas veces se refiriera a la incesante marcha del saber filosófico, cobra viva presencia en su gran producción intelectual. Al cumplirse en setiembre 10 anos de su muerte, publicamos este trabajo en agradecido homenaje a quien nos puso tras la huella del pensar la realidad.
\end{abstract}

Esta es una reflexión en torno a la idea de realidad en Xavier Zubiri. El estudio de problemas vigentes en nuestro tiempo, la rigurosidad en el tratamiento de los mismos y la apertura de vías intelectuales fecundas, son tres condiciones que reúne la obra de este filósofo español y significan una importante contribución a nuestro esfuerzo por ahondar en la comprensión de lo real. La filosofía de Zubiri reviste un carácter metafísico y sistemático - tomamos aquí sistemático en su sentido lato, independientemente del sentido especial y preponderante que adquiere la idea misma de sistema en su contexto-. Una primera lectura de Sobre la Esencia, su obra metafísica por excelencia, podría hacernos pensar que se trata de una interpretación más de la metafísica clásica, dado el prolongado tratamiento que allí emprende de temas como esencia y existencia, el ser, los transcendentales, etc. Y es que como toda auténtica filosofía, la obra de Zubiri no parte de tabla rasa 
sino que se edifica y adquiere consistencia en estrecho diálogo con la tradición metafísica occidental desde Parménides. Pero lo que está a la base de este diálogo es justamente una nueva idea de realidad, con lo que queda intrínseca y radicalmente modificado el contenido mismo de la metafísica. En la Introducción a Sobre la Esencia dice Zubiri "Al hilo de la transformación del concepto de realidad como sustancia, ha ido transformándose el concepto de 'lo que' es esta realidad, a saber la esencia. Por singular paradoja nos hallamos, pues, ante el mismo problema con el que tuvo que debatirse el propio Aristoteles: la implicación entre la estructura radical de la realidad y la índole de su esencia". (1)

No podemos realizar aquí un detallado análisis de la metafísica zubiriana, tarea que reviste gran importancia, pero que rebasa los límites de esta reflexión. Sólo hemos de ceñirnos a su punto de partida: la idea de realidad, para señalar una posible línea interpretativa de este pensamiento. En última instancia, la ingente labor filosófica de Zubiri, no es sino la justificación plenaria de esta nueva idea de realidad.

Para su mejor comprensión, hemos ordenado nuestra exposición en dos pasos:

1.- La realidad como carácter físico de las cosas.

La primera aproximación a la índole de lo real que efectúa Zubiri en Sobre la Esencia, es a propósito de la delimitación del "ámbito de lo esenciable", esto es, el ámbito sólo dentro del cual existen las cosas que poseen esencia -entendiendo aquí, en un sentido muy amplio, la esencia como aquellas notas que ha de tener necesariamente una cosa para ser tal-. Allí nos dice que este ámbito de lo esenciable coincide justamente con el ámbito de realidad y a continuación define: "Es realidad todo y sólo aquello que actúa sobre las demás cosas o sobre símismo en virtud, formalmente, de las notas que posee". (2)

Esta definición requiere ciertas explicitaciones. En primer lugar

(1) Zubiri, X.: Madrid, Sobre la esencia; Soc. de Estudios y Publicaciones, 1972, pág. 9

(2) Ibidem, pág. 108 
¿Qué significa aquí "nota"?. Es un término muy utilizado por Zubiri y se refiere a todo aquello que pertenece a la cosa o que forma parte de ella "en propiedad", como algo "suyo". No es la propiedad (proprium) aristotélica, que supone la cosa ya constituída, sino que incluye los momentos constitutivos mismos de la cosa. Hecha esta aclaración, Zubiri hablará indistintamente de "nota" o de "propiedad". Así, por ejemplo, son notas o propiedades del hombre la psique, el organismo, la inteligencia, la voluntad, la sensibilidad, etc., es decir, todo aquello que le pertenece "en propio".

En segundo lugar, el concepto de realidad queda determinado por la actuación (de una cosa sobre otras o sobre sí misma). Pero debemos precisar la índole de esta actuación porque de ella surgen importantes consecuencias. Hemos dicho que al determinar el ámbito de las cosas que poseen esencia nos encontramos con el ámbito mismo de la realidad, esto es: sólo las cosas reales poseen esencia. Y las cosas reales quedan determinadas por su actuación, más exactamente por su actuación real. Se trata de la actuación física de unas cosas sobre otras. ¿Qué se entiende aquí por "físico"?. Zubiri concede gran importancia a este vocablo y dedica una Nota General en Sobre la Esencia a determinar su sentido. Allí afirma que físico y real, en sentido estricto son sinónimos. Este sentido estricto, debe entenderse en la línea de lo real como contrapuesto a lo intencional o conceptivo. "Lo inteligido en cuanto tal, no es una parte física de la inteligencia; pero en cambio, el acto mismo de inteligir es algo físico. Aqut, pues, lo físico se contrapone a lo intencional. Y de aquí físico vino a ser sinónimo de real, en el sentido estricto de este vocablo". (3)

Si Zubiri se preocupa por remarcar con insistencia el carácter físico de lo real, es para advertirnos su modo de acceder al objeto de la metafísica, modo que podríamos denominar "vía física" para contraponerla a la "vía conceptiva" que, según Zubiri, ha seguido la tradición metafísica desde Aristóteles. Este es un tema decisivo en la interpretación del pensamiento zubiriano pues en él estriba su verdadera novedad: lo que propone es un acceso sentiente y por tanto, directo, a la realidad

(3) Ibidem., pág. 16 
en cuanto tal, en lugar de un acceso mediado por la actividad concipiente de la inteligencia. Claro está que, con ello, habrá que reformular el carácter mismo de la intelección humana: es el paso de una inteligencia concipiente a una inteligencia sentiente, tema que abordaremos en el segundo punto de este trabajo.

Pero nos queda por precisar algo más sobre el carácter físico de lo real. Desde lo dicho al determinar el ámbito de las cosas reales, es decir, el ámbito de lo esenciable por la actuación física, podría pensarse que lo real coincide aquí con lo natural. Estaríamos en la postura de Aristóteles. Es bien conocida su delimitación de los entes naturales como aquellos que en rigor tienen esencia -sólo de los cuales puede haber definición en sentido estricto- frente a los entes artificiales, que no tienen verdaderamente esencia. En definitiva, para Aristóteles, el ámbito de lo esenciable queda acotado a la naturaleza por contraposición a la tekhne. Pero no es en esta línea de lo natural como Zubiri entiende lo físico, y en su consideración crítica de esta dualidad entre naturaleza y tekhne, nos pone ante un importante problema de la filosofía contemporánea. En efecto, reconoce Zubiri que naturaleza y tekhne son, por un lado, dos principios de las cosas, y en este sentido se contraponen y excluyen en la forma que nos dice Aristóteles: en la tekhne, este principio es extrínseco a las cosas, se halla en la imaginación o en la inteligencia del hombre; en la naturaleza, en cambio, el principio es intrínseco a las cosas. Pese a ser verdad, esto es radicalmente insuficiente, porque esta dualidad de principios no envuelve necesariamente una dualidad adecuada en la entidad de los entes principiados. "Tal vez la técnica griega-dice Zubiri-, y en general toda la técnica antigua, sólo pudieran realizar 'arte-factos', esto es, cosas que la naturaleza no produce y que una vez producidas no tienen 'actividad natural'. En este caso, la dualidad de principios conduce a una dualidad de entidades. . . Pero en nuestro mundo, esto no es verdad. Nuestra técnica no sólo produce arte-factos. . . sino también las mismas cosas que la naturaleza produce y dotadas de idéntica actividad natural. Y en esta mismidad se halla lo decisivo. Un abismo separa nuestra técnica de la técnica antigua; no es sólo una diferencia de grado, sino una diferencia fundamental, de incalculable alcance filosófico. . . En estas condiciones, la diferencia entre arte-factos y 
entes naturales desaparece: 'nuestra técnica produce artificialmente entes naturales'. . . Esta es la idea de la nueva técnica. Para un griego esa frase constituiria la más inadmisible paradoja. En su virtud la dualidad de physis y tekhne, válida en el orden de los principios, deja de serlo en el orden de los entes principiados". (4)

Ahora bien, si como queda dicho, el carácter físico de lo real no se determina como en Aristóteles desde lo natural, el área de la realidad queda circunscripta con rigor para Zubiri por contraposición a las cosassentido. Expliquemos esto. Hemos visto que es real todo y sólo aquello que actúa en virtud, formalmente, de las notas que posee. En este sentido los minerales, los seres vivos, los hombres, etc., son cosas reales. A estas cosas se contraponen otras tales como una mesa o una vivienda, que son en cierta forma reales, pero lo son tan sólo por las propiedades o notas de peso, solidez, densidad, color, etc. por las cuales actúan sobre otras cosas. En cambio no actúan sobre las demás cosas por su carácter formal de mesa o vivienda, porque este carácter no es una propiedad real "suya", es decir, no es un momento de su realidad. De ahí que estas cosas no sean formalmente reales sino justamente otro tipo de cosas: son "posibilidades de vida", esto es, cosas que se constituyen sólo desde el "sentido" que cobran las cosas reales para la vida humana. Posibilidad y nota real son, entonces, dos dimensiones distintas de la cosa, de las cuales, la primera se funda en la segunda; y ésto, importa mucho destacar, no sólo por la anterioridad "física" de la realidad sino por el modo primero y primario como la cosa es percibida. Esta distinción entre cosa-real y cosa-sentido, que sólo enunciamos aquí para delimitar con cierto rigor nuestro tema, adquiere un interesante despliegue cuando Zubiri aborda el tema de el hombre como realidad personal y más especialmente, el tema de la historia.

\section{La realidad como carácter formal de lo aprehendido en impre- sión.}

Hasta aquí el problema de la realidad pareciera encauzarse por las vías del realismo gnoseológico; se trata de la índole propia de las cosas,

(4) Ibidem, pág. 88-89. 
tal como son "de suyo". Sin embargo en Sobre la Esencia, a pocas páginas de la definición que acabamos de analizar, reaparece el tema de la realidad con otro matiz: Aquí realidad no significa lo que la cosa es en sí misma, su naturaleza, etc., sino que . . ."significa tan sólo el carácter formal de lo aprehendido, aunque lo aprehendido sea la cualidad más efímera, fugaz e insignificante". (5)

Esta afirmación podría sugerir que sin aprehensor, no habría realidad, lo cual colocaría a Zubiri, cuando menos en la línea de un subjetivismo. Pero, como veremos, en el contexto de su filosofía, lo que en verdad no habría sin aprehensor es la realidad como problema, y en esto no pueden sino coincidir todas las filosofías. Lo decisivo entonces, es la idea de realidad que aquí está en juego.

En este punto debemos fijar nuestra atención porque en él se articulan los dos temas nucleares de la filosofía zubiriana: realidad e intelección sentiente. La índole de esta articulación, expresada en los términos "formalidad de realidad" o "carácter formal de realidad", determina el modo de acceder la inteligencia al objeto de la metafísica: lo real en tanto que real. En rigor, debemos decir que no se trata para Zubiri de un acceder, sino de un ahondar en el carácter último de aquello en que ya estamos irremisiblemente instalados, a saber, la realidad.

Realidad e intelección sentiente conforman en esta filosofía una estructura unitaria, que podemos abordar desde su versión a la realidad, desarrollada en Sobre la Esencia, o desde su versión a la intelección, que Zubiri despliega en su obra posterior, la trilogía Inteligencia Sentiente, Inteligencia y Logos e Inteligencia y Razón. En el Prólogo a Inteligencia Sentiente, el filosofo señala el rumbo de una adecuada interpretación de su pensamiento. Allí dice: "Publico este libro sobre la inteligencia muchos años después de haber publicado un libro sobre la esencia. Esto no es mera constatación cronológica. . . es que es imposible una prioridad intrínseca del saber sobre la realidad ni de la realidad sobre el saber. El saber y la realidad son en su misma raiz estricta y

(5) Ibidem, pág. 118 
rigurosamente congéneres. No hay prioridad de lo uno sobre lo otro. Y esto no solamente por condiciones de hecho de nuestras investigaciones, sino por una condicion intrinseca y formal de la idea misma de realidad y de saber. Realidad es el carácter formal -la formalidadsegún el cual lo aprehendido es algo 'en propio', algo 'de suyo'. Y saber es aprehender algo según esta formalidad". (6)

En torno a nuestro tema, nos queda por explicar qué significa inteligir, pues lo que allí se nos mostrará es el carácter "formal" de lo aprehendido en impresión.

Zubiri comienza el análisis de la intelección señalando la separación entre sentir e inteligir que, desde Parménides, ha venido gravitando -bien que con diferentes matices- sobre toda la filosofía europea. "Se nos dice a lo sumo que los sentidos dan a la inteligencia las cosas reales sentidas para que la inteligencia las conceptúe y juzgue de ellas. Pero sin embargo no se nos dice ni qué sea formalmente sentir, ni sobre todo, qué sea formalmente inteligir". (7)

Para Zubiri la intelección no es acto de una facultad ni de una conciencia, sino que es en sí misma un acto de aprehensión. En efecto, el acto intelectivo es un "estar" en que yo estoy "con" la cosa y "en" la cosa, y en el que la cosa está, a su vez, "quedando" en la intelección. Ahora bien, este acto, de carácter aprehensivo, pertenece también al sentir. Por lo tanto, es en la línea del sentir, o más exactamente, en la contraposición del sentir del animal -que es "mero" sentir- y el sentir humano -que es sentir intelectivo- donde hallaremos la índole constitutiva del inteligir. El sentir del animal y el sentir del hombre, no difieren por el contenido de lo aprehendido, sino por el modo como lo aprehendido "queda" en el aprehensor. En el animal, lo aprehendido queda tan sólo como perteneciendo al proceso sentiente, es decir, integramente abocado a la respuesta. En el hombre, en cambio, lo

(6) Zubiri, X.: Inteligencia sentiente; Madrid, Alianza Editorial, 1980, pág. 10-11

(7) Ibidem, pág. 12 
aprehendido en impresión no queda tan sólo como perteneciente al proceso del sentir sino que queda, por sí mismo, o mejor, desde sí mismo, como siendo ya algo "suyo" o "en propio" (en el sentido explicado en la primera parte de este trabajo). Y en esto consiste precisamente la formalidad, en el modo como lo aprehendido queda en el aprehensor: en el animal se trata de una formalidad estimúlica, por ello es "mero" sentir; en el hombre se trata de formalidad de realidad, por ello es sentir intelectivo. Sentir intelectivo o inteligencia sentiente son las denominaciones de un acto único: impresión de realidad. Inteligir no es para Zubiri sino un modo de sentir: sentir la realidad.

Dos aspectos debemos señalar sobre el carácter formal de lo real. En primer lugar, no se trata de ir allende lo aprehendido en la aprehensión, sino del modo como lo aprehendido "queda" en la aprehensión. "La realidad no es algo a lo que haya que ir, sino que es primariamente algo en que ya se está y en que... nunca se dejará de estar". (8)

En segundo lugar, la formalidad de realidad es algo en virtud de lo cual lo aprehendido es "ya" lo que es anteriormente a su propia aprehensión. Lo real captado en aprehensión es un "prius" respecto de la aprehensión.

Paradojalmente, la filosofía de Zubiri, que demanda un gran esfuerzo intelectual dado el carácter sumamente precisivo de sus análisis y el rigor de sus desarrollos conceptuales, nos deja sin embargo en su misma base ante un hecho, que por ser tan modesto $y$ elemental, ha permanecido oculto tras la ingente edificación especulai iva de Occidente: se trata de la instalación radical del hombre en la realidad. Instalación que surge de una imperiosa urgencia biológica: el tener que hacerse cargo de lo que es "en realidad" aquello que lo estimula, para hacer viable su existencia. Haber elevado este hecho a la altura de la filosofía con su ulterior despliegue en riqueza y profundidad es, a nuestro modo de ver, uno de los aportes más valiosos del pensamiento de Xavier Zubiri.-

(8) Ibidem, pág. 250 


\section{RESUMEN}

Este trabajo constituye una reflexión en torno a la idea de realidad en $X$. Zubiri. La obra de este pensador se edifica en estrecho diálogo con la metafísica occidental; pero lo que está a la base de este diálogo es una nueva idea de realidad, con lo que queda intrínsecamente modificado el contenido mismo de la metafísica.

Hemos ordenado nuestra exposición en dos pasos:

\section{1. - La realidad como carácter físico de las cosas.}

El concepto de realidad queda determinado para Zubiri por la actuación "física" de unas cosas sobre otras. Físico y real son sinónimos en el sentido de contrapuestos a intencional o conceptivo.

\section{2. - La realidad como carácter formal de lo aprehendido en impresión.}

En este punto se articulan dos temas nucleares de la filosofía zubiriana: realidad e intelección sentiente, que conforman una estructura unitaria. Para Zubiri, la intelección no es acto de una facultad ni de una conciencia, sino que es en sí misma un acto de aprehensión, que como tal pertenece también al sentir. En el hombre, lo aprehendido en impresión queda "desde sí mismo" como siendo ya algo "de suyo" o "en propio" (en el sentido desarrollado en el punto 1). 